\title{
Merger of Burger King and Tim Hortons: analysis of marketing strategies in the quick service restaurants
}

\author{
Etienne Musonera \\ Stetson School of Business and Economics, \\ Mercer University-Atlanta, \\ 3001 Mercer University Drive, Atlanta, \\ GA 30341, USA \\ Email: Musonera_e@mercer.edu
}

\begin{abstract}
Restaurant Brands International Inc. is a Canadian quick service restaurant company. It was created by the merger of Canadian coffee shop restaurant chain Tim Hortons and the US fast food restaurant chain Burger King in 2014 and expanded by the purchase of Popeyes in 2017. The company is the fifth-largest operator of fast food restaurants in the world with more than 25,000 restaurants operating in over 100 countries under its distinct brands. The merger's primary focus is to expand the international reach of the 'iconic' Tim Hortons brand, and provide financial efficiencies for both companies. In this case analysis, we looked at the past and present situation and addressed business issues facing both Burger King and Tim Hortons. We conducted a systematic case analysis, and used Michael's Five Forces to assess industry attractiveness. We identified problems and issues facing both companies, and we developed a set of strategic alternatives for the new company. We also evaluated and recommended sustainable alternatives marketing strategies to achieve superior results.
\end{abstract}

Keywords: merger; Burger King; Tim Hortons; marketing strategies; Michael Porter's Five Forces.

Reference to this paper should be made as follows: Musonera, E. (2019) 'Merger of Burger King and Tim Hortons: analysis of marketing strategies in the quick service restaurants', Int. J. Strategic Business Alliances, Vol. 6, No. 4, pp.267-283

Biographical notes: Etienne Musonera is an Associate Professor of Marketing in the Eugene Stetson School of Business and Economics at Mercer University. He teaches Marketing Management Strategy, Project Management, Business/ Marketing Research, Operations and Production Management, International and Marketing Management. $\mathrm{He}$ worked for General Motors as a Manufacturing Quality Systems Engineer and travelled to GM's plants across Canada and USA overseeing manufacturing quality systems engineering and project management activities. He consults on marketing strategies, foreign direct investment, decision risk analysis, Lean Six Sigma, business process management, project engineering management, quality management, and world class manufacturing (WCM) best strategies and practices. 


\section{Introduction}

\subsection{Burger King}

Burger King (BK) was first established in 1952 in Miami under the name of 'Insta-Burger King' by Keith Cramer who launched the chain by using a broiler that was able to cook 400 burgers in an hour. Later in 1954, the chain was renamed by David Edgerton, who called it 'BK' and came up with an improved version of the burger: 'the flame-broiled burger' (http://www.bk.com). It was in the same year, 1954, that David along with Jim McLamore started the BK Inc. (Daszkowski, 2018). In 1957, BK introduced its Whopper sandwich, which was made of ripe tomatoes, fresh crisp lettuce and dill pickles. With its first ad campaign 'Home of the Whopper', the appealing sandwich became an instant hit, while prices remained low (Daszkowski, 2018). Furthermore, with its self-service ordering and comfortable outdoor seating, BK was able to differentiate itself and became the first chain to offer dining rooms. In 1961, led by McLamore and David, BK was able to obtain its first international franchise rights (Daszkowski, 2018). In 1962, BK opened its first international franchisee in Puerto Rico.

In 1967, Mr. McLamore and Mr. Edgerton sold BK to Minneapolis-based Pillsbury Company, which was able to take it from a privately-held franchised chain to a large food corporation. In December 2002, BK was acquired by private equity funds controlled by TPG Capital, Bain Capital Partners and the Goldman Sachs Funds. In 2006, BK completed its initial public offering (Reuters, 2010). Throughout the years many marketing campaigns have been launched to increase the publicity of the fast-growing restaurant chain. For instance, 'Have It Your Way ${ }^{\circledR}$ ' campaign in 1974 introduced the drive-thru service, which was designed to satisfy customers 'on-the-go' in 1975. BK continued its attempts to win bigger share of the market by introducing new products, switching to healthier ingredients, and launching more campaigns. In 1993, BKs' share was $6.1 \%$ compared to $15.6 \%$ of McDonalds despite its improved version of the campaign 'your way, right way' (Baer, 2012). This campaign targeted health conscious customers by switching to vegetable oil for frying French fries. These failed campaigns were attributed to the company's failure of providing a proper mix of products and messages.

Many factors contributed to the decline in sales, such as negative attitude toward fast food, aggressive competition, and anti-obesity campaigns. Moreover, several internal factors, such as improper brand management, lack of customer orientation, and weakness in new product positioning have attributed to the drop in sales. After 2003, a group of investors led by Texas Pacific Group acquired BK and undertook major enhancements to help recover the business and revitalise its brand's image (York, 2010). Among those enhancements are organisational restructuring, changing management culture, new agreements with advertising agencies and menu revamp (http://www.bk.com).

\subsection{Tim Hortons}

Tim Hortons, wholly-owned by Restaurant Brands International, is one of Canada's largest fast food restaurant and was founded in 1964 in Hamilton, Ontario. Ronald V. Joyce opened the first franchisee of store in 1964 and in 1967 he became partner with the famous hockey player Tim Horton, whom the store was named after (Hunter, 2018). He died in 1974 in a tragic accident. The store started out as a small 
coffee shop offering coffee and donuts with the Apple Fritter and the Dutchie (Hunter, 2012; Penfold, 2008). However, the leading scorecard is the legendary Tim Hortons coffee, which is available in cans, as well as the hot chocolate, English toffee and French vanilla cappuccinos, provides customers with convenient enjoyment (http://www.timhortons.com).

Tim Horton quickly expanded into serving a variety of baked goods and home style meals that appeal to customers throughout the day. Its wide range of soups, sandwiches and chillies created strong influence for customer to dine at Tim Hortons during various occasions. Tim Hortons continuous product innovation is the main ingredients in its success triumphant. Its biggest success was the release of the timbit, a bit-sized donut-hole, which they trademarked 'timbits'. The timbit marked a significant symbol of their success offering over 39 varieties in 35 different flavours attracting customers of all ages especially youngster. The heart of the company commitment to continuously exceed customer expectation is its core value to always deliver top quality, fresh product, value, exceptional service and community leadership. These core marketing strategies rapidly led the store to expand into one of Canada's largest fast food restaurant chain. The chain dominates the fast food sales with $28 \%$ in Canada, including $75 \%$ of the entire coffee and caffeinated beverage sales (http://www.timhortons.com).

Tim Hortons' system wide has 4,590 restaurants, including 3,665 in Canada, 869 in the US and 56 in the Gulf Cooperation Council. The Tim Hortons expansion concept into the US market are visible in Michigan, New York, Ohio, Kentucky, Maine, and West Virginia with key marketing position in shopping malls, highway outlets, universities and hospitals catering to on the go consumer.

In 1995 Tim Hortons merged with Wendy's International Inc.; in 1996 Tim Hortons added bagels; in 2006 Tim Hortons opened its 3,000th restaurant; in 2008 Tim Horton opened 500 restaurants in the US and in August of 2014, Tim Hortons merged with BK to create the world's third largest quick service restaurant (QSR) in the fast-food restaurant chain. The merger is estimated to generate approximately $\$ 22$ billion in sales and establish a global powerhouse of more than 25,000 restaurants in 100 countries. According to Tim Hortons CEO, Marc Caira, "the merger will allow Tim Hortons to compete globally with Starbucks Corporation and Dunkin' Brands Group, which have been aggressively expanding overseas, particularly in Asia" (http://www.timhortons.com).

\section{Environment analysis}

\subsection{Economic conditions and trends}

The industry description for Tim Hortons and BK is categorised as fast-food operated within the QSR segment of the restaurant industry. According to multiple market reports, Fast food restaurants represent one of the fastest growing segments of the food industry because of its convenience and low-cost (https://www.statista.com/statistics/196619/totalnumber-of-fast-food-restaurants-in-the-us-since-2002/). According to 2011 market research by IBIS World, the fast food industry generates about $\$ 165$ billion in revenue annually with approximately 184,200 fast food businesses operate in the US (https://fastfoodinusa.com/types-of-economic-factors-that-can-affect-the-fast-foodindustry/). However, long-term recession can hurt the fast food industry as consumers 
turn into eating at home more often to save money. Under such conditions, most big restaurant chains respond by further cutting of their prices and intensifying their advertisement campaigns to lure customers back to their restaurants. On the other hand, small chains usually do not have financial capability to face such challenges. Thus fast food chains sometimes merge during a recession to capture a larger share of the market and increase profit. In August of 2014, Tim Hortons and BK merged to create the world's fifth largest fast-food restaurant chain.

The merger was to generate approximately $\$ 22$ billion in sales and establish a global powerhouse of more than 25,000 restaurants in 100 countries. According to Tim Hortons CEO, Marc Caira, "the merger will allow Tim Hortons to compete globally with Starbucks Corporation and Dunkin' Brands Group, which have been aggressively expanding overseas, particularly in Asia" (https://www.forbes.com/sites/ greatspeculations/2014/08/29/burger-king-tim-hortons). Mergers usually help fast food restaurants to expand their customer base and both companies' combined signature products will lead to higher revenue and bigger market share. Marketing reports by Forbes (http://www.forbes.com), indicated that despite the strong market demand for Tim Hortons brand in Canada, the company is struggling to create a similar presence in the US market. On the other hand, BK in US is battling a fierce competition from the fast growing fast-casual segment as well as the breakfast segment (Forbes, 2014b).

\section{Cultural and social values and trends}

\subsection{Cultural value and social trend}

The cultural and social values of fast food industry differ from country to country and region to region. Drive-thru and Food-on-the-go are common trends in the US. Research shows that over $75 \%$ of US consumers dine out at fast-food restaurant at least once a week (https://www.statista.com). In contrast, people of the European nations enjoy dining in and sharing meal time with families. Fast food industry and regional QSRs have taken the above trends in consideration and customised their layout and menu offerings to target different geographic and demographic segments (transparency market research). BKs' social value is to serve customers with the best quality fast food.

Over the last 50 years of operations, BK was able to create a distinctive restaurant experience that offers customers quality fast food at affordable prices. Tim Hortons' values, beliefs and slogans are also embedded in its organisational culture. Tim Hortons' is committed to provide its customers with quality products that are reliable and part of our everyday lives as evident from its slogan 'always fresh' and 'always there' (http://www.timhortons.com).

\subsection{Political and legal issues}

The fast food industry must comply with country-specific political and legal requirements. Investors have to abide with political requirements and regulations, such as minimum wage, hygiene and quality regulations, which in turn can impact the cost and quality of products. For instance, the initiative by the US Government to improve consumers' eating habits has forced fast food chains to promote healthy eating behaviours, such as including calorie information on their products. 
Additionally, the merger between BK and Tim Hortons has its political and legal issues. BK had to comply with certain conditions, such as, first maintaining the existing employment rate at Tim Horton franchises across Canada while expanding in the US and globally. Second, the company will have to move its headquarters to Oakville, Ontario from Miami, FL and list the company on the Toronto Stock Exchange. Third, to manage Tim Hortons as a separate brand, without co-branding any locations in Canada or in the US. Finally, to maintain the Canadian franchisee rent and royalty structure at current levels for five years and ensure Canadians constitute at least $50 \%$ of the Tim Hortons' board (Evans, 2014). While inversions have occurred in the past, the popularity of this merger trend increased following the Great Recession. In fact, nearly two-thirds of US outbound mergers in 2014 were structured as inversions, which is up significantly from $1 \%$ in 2011 (Raice, 2014).

As more firms pursue inversions, President Obama has urged Congress to prevent these transactions from occurring in the future. While this does not have a direct impact on BK, new legislations could prevent firms from employing the same strategy in the future. While President Obama works to curtail inversions from occurring, the Canadian Government is actively encouraging firms to relocate to Canada. In 2012, the Canadian Government lowered the federal corporate tax rate from $28 \%$ to $15 \%$ (Hodge, 2012). "According to a recent KPMG report, Canada is one of the most business-friendly countries in the world" (Woodland, 2014).

\subsection{Summary of environmental opportunities and threats}

As the new company continues to make giant strides internationally, global trend in consumers' lifestyles and eating habits will present threats as well as opportunities for the chain. However, the joint strong brand image of Tim Hortons and BK will resonate in consumers' mind the imaginary of continuous menu innovations to satisfy their evolving needs. The company brand promise is to delight every consumer who comes in contact with its brand by providing superior quality products/services and the ultimate guest experience (Caira, 2013). It is obvious that customer relation is the cornerstone of the company's vision.

In its effort to continuously provide ultimate customer satisfaction, the company has integrated several new operational initiatives such as new mobile payment options. Nonetheless, increasing concerns about health and diet will create intense competition globally from local small fast food restaurants who are offering healthier menu from locally grown produce at similar or lower prices. This creates brand loyalty for local restaurants as consumers believe that their support in local restaurants will boost economic growth in their county. This forces international competitors to customised menu offerings and prices to satisfy customers' values and lifestyles in the country they are living. Redesigning menu and pricing to adapt to the needs of customers across foreign markets can adversely impact profitability as this can be very expensive for the company. For example in Europe the Triple Whopper is served without cheese, while the customers in the USA expect their Triple Whopper to be served with cheese (ibisworld). In addition, the merger of both brands was criticised by most consumers as a tax inversion strategy for BK to gain tax benefits. BK denies the allegation stating that the deal is to bring both chains together to create new dimension of aggressiveness in the international market (Forbes). 


\subsection{Implications for strategy development}

The strategic alliance and merger of two of the most respected and well-known fast-food giants in over 100 countries will definitely create a world of international opportunities providing the chain with strategic advantage in a competitive intensity world. They will have greater marketing fuel to experiment in new countries that have been identified with high growth potential.

Another benefit is that the new company will also gain greater profitability by providing consumers with a one-stop shopping experience that cut down on time and price. The already established strong demand for Tim Hortons' famous coffee sector combined with BK innovating tempting whooper will undoubtedly let the chain standout from its competitors creating a substantially wider customer based in the breakfast segment and give it sustainable advantage in the breakfast market.

\section{Industry analysis: Michael Porter's Five Forces}

\subsection{Classification and definition of industry}

Tim Hortons operates in the donut/coffee/tea category of the QSR segment of the restaurant industry. In North America, the QSR segment is the biggest segment of the restaurant industry and has shown long-term growth. According to Statica (2019), consumers spent \$285 billion in the QSR segment in North America in 2014 and 33\% of the Canadian QSR segment was in the donut/coffee/tea category. In 2018, the QSR sector generated 299.6 billion US dollars in consumer spending (statica.com).

\subsection{Analysis of existing competitors}

Restaurant International major competitors are Dunkin brands, Starbucks, McDonald's, Wendy's, Hardee's restaurants, Panera Bread, Starbucks, Subway, and Wendy's. Analysis of Potential New Entrants: The restaurant industry has few barriers to entry, and therefore new regional competitors may emerge at any time. However, due to the large capital and long timeframe required, the risk of a new competitor on a national or international scale is low.

\subsection{Analysis of substitute products}

The donut/coffee/tea category of the QSR segment of the restaurant industry competes for consumer dollars with QSRs that offer alternative menus, casual and fast casual restaurant chains, convenience stores, grocery stores, and various different styles of home-brew coffee machines. As people awareness of health problems associated with eating fast-food increases, the strength of substitute became higher as consumer eating habit as shifted from fast-food high calorie foods in favour of healthier menu options.

This new trend in consumers' dietary preference gives birth to the emergence of substitutes products namely Chipotle Mexican Grill, Boston market, and Panera Bread Company. These new chains offer customers faster healthy foods at premiums prices than traditional restaurants. They are positioned in the QSR industry as 'fast-casual' appealing to a rapid growing health conscious consumer trend. Another growing popularity 
alternative to traditional fast- food service is quick meals offered at supermarket, convenient stores and vending machines to accommodate the fast pace of consumers' lifestyles.

In contrast, the risk of substitute product for coffee and donuts remain low because of the organic nature of these foods. However, by combining the reputation of two of the world's most respected, renowned brands, Tim Hortons and BK, Restaurant Brand International will certainly create the most powerful fast-food chain in the world. Restaurant Brand International could compete on a more aggressive worldwide platform in uniqueness, high quality food, menu innovation and value.

\subsection{Analysis of suppliers}

Tim Hortons has suppliers for food, packaging, and the equipment in their stores. They strategically utilise their own manufacturing facilities in the best interest to protect their supply chain. For example, Tim Hortons roasts and blends their coffee in-house in order to guard the proprietary blend recipe. Also, they make their own donut fondant and fills, although they are currently in a contract with a third party supplier that requires them to purchase all of their actual donuts from a single supplier until early 2016. The rest of the raw ingredients and materials, such as wheat, oils, and sugar, are purchased from multiple suppliers and they generally have alternative sources for each.

While Tim Hortons has multiple suppliers of coffee beans, their supply and price can fluctuate dramatically, which is why Tim Hortons purchases future contracts for their coffee beans. Tim Hortons acts as its own distributor in Canada but distributes through a third party in the US. Due to their large size, their in-sourcing abilities, their futures contracts, and their ability to find multiple sources, the power of Tim Hortons' suppliers is relatively low. The one exception might be the donut supplier that currently has an exclusive arrangement, but due to the huge volumes involved, it is likely that they are just as reliant on Tim Hortons as Tim Hortons is on them.

\subsection{Analysis of buyers}

Tim Hortons' buyers are the end-customers that purchase donuts, coffee, and tea in their restaurants. These buyers have a great deal of power because it is not difficult at all for them to take their business to a competitor or substitute. There are many things that can affect large numbers of buyers, such as large and sustained movements in the overall economy, outbreaks of foodborne illness tied to Tim Hortons, and lawsuits against Tim Hortons. Tim Hortons proudly promised to be bold, different and daring while BK's promise is to 'have it your way'. Both companies' track records exuberate through their unmatchable customer experience.

\subsection{Summary of industry opportunities and threats}

An abundance of recent market studies has proven that QSR is the largest growing segment of the restaurant industry and that the sector seems to be least vulnerable to economic downturn largely in part because consumers shift their purchases downward when disposable income is low (http://www.qsrmagazine.com). Therefore, as Restaurant Brand International continues its expansion strategy to widen its footprint across 
international markets, the chain will continue to maintain its value by providing superior quality products/services and the ultimate guest experience.

Both giants are collectively committed to introducing new product variety and nutrition, health and wellness across demographics and culture diversity to satisfy the inevitable growing changes in consumers' tastes and preferences. The merger will boost revenue from accelerated international growth and generate costs savings for both companies. The combined efforts of these two fast-food giants will have greater purchasing power, economies of scale and efficiencies in marketing and operations and an opportunity to expand their unique brands.

\subsection{Summary of firm's strengths and weaknesses}

Restaurant Brands International Inc. is a new global QSR formed by the merger between BK Worldwide Inc. and Tim Hortons (CSP Daily News). BK is the second largest fast food hamburger chain in the world, while Tim Hortons is the largest coffee and doughnuts seller in Canada. The joined business is expected to generate about $\$ 22$ billion in sales and create more than 25,000 restaurants in 100 countries (Viera, 2014). Although both companies will maintain their distinctive brands and continue to operate separately, the two iconic chains will benefit from the deal. The merger with Tim Hortons provides BK with several advantages including additional revenues, tax savings, improved menu resources, and further international expansion (Forbes, 2014a).

Similarly, the merger with BK would help Tim Hortons skilfully progress from fair-running national restaurants to the edge of international dominance. BK has been facing an aggressive competition from the merging fast-casual segment as well as the breakfast segment. In a market where coffee is an essential breakfast item, BK's goal is to expand this segment and compete with McDonald's McCafe and Starbucks' distinctive coffee (Forbes, 2014b). The merger would provide both brands the opportunity to strengthen their weakness points, upsurge their purchasing power, advance their marketing and operation efficiencies, and reinforce their opportunity for brand expansion.

\section{Organisation}

\subsection{Objectives and constraints}

Tim Hortons Inc. and BK will form the world's third-largest fast-food company. Restaurant Brands International was created with a primary objective, which is to expand the international presence, and provide financial efficiencies for both companies. BK agreed to pay $\$ 11$ billion to buy the Canadian chain Tim Hortons in August 2014; however, the deal was closed on 10 December 2014 after BK agreed to comply with the Canadian Government's conditions (Viera, 2014). Some of those conditions include maintaining the existing employment levels at Tim Hortons franchises across Canada; shifting its headquarter to Oakville, Ontario from Miami, FL; and listing the company on the Toronto Stock Exchange. Moreover, managing Tim Hortons as a separate brand without co-branding any location either in the US or Canada; maintaining the Canadian franchisee rent and royalty structure at current levels for five years; and making sure Canadians make up at least $50 \%$ of the Tim Hortons board (Viera, 2014). Furthermore, the above deal has created a controversy among decision makers due to tax-issues. 
BK has incorporated abroad by shifting its corporate citizenship to Ontario, Canada. When a company shifts its corporate citizenship, it's usually trying to pay less in taxes. "Canada has a much lower corporate tax rate: 15 percent at the federal level plus another 11 percent on average from provincial corporate taxes. Compare that to the US federal corporate tax rate of 35 percent plus an average state corporate tax rate of about 4 percent" (McBride, 2014). Therefore, the merger has been looked upon as tax inversion by BK. BK has been accused of taking advantage of the deal, since shifting the headquarters to Canada will benefit the American company in tax savings. The merger is expected to save BK an estimated $\$ 400$ million to $\$ 1.2$ billion in US taxes between 2015 and 2018 (International Business Times, 2014). The deal was not favoured by the White House as well as many of the public who expressed their dissatisfaction on social media, such as Facebook and Twitter (Viera, 2014).

\subsection{Financial condition}

Restaurant Brands International is a Canadian multinational fast food restaurant company, which was formed by the $\$ 11$ billion merger of $\mathrm{BK}$ and the Canadian chain Tim Hortons (Inskeep, 2014). The combined company will be the third-largest restaurant operator in the world, after McDonald's Corp. and Yum! Brands Inc. (Maze, 2014). The new merged company would have approximately $\$ 23$ billion in sales and more than 18,000 locations in 100 countries under its two separate brands (Viera, 2014). Effective 12 December 2014, shares of Tim Hortons and BK Worldwide common stock have stopped trading on the Toronto Stock Exchange and New York Stock Exchange, respectively. Restaurant Brand International common shares began trading on the Toronto Stock Exchange and New York Stock Exchange under the trading symbol QSR (Viera, 2014).

\subsection{Organisational structure}

3G Capital (which held a $71 \%$ majority stake in BK) holds a $51 \%$ majority stake in Restaurant Brands International. The remainder of the company is publicly traded on the New York and Toronto Stock Exchanges, and owned by the prior shareholders of BK and Tim Hortons. Tim Hortons' existing shareholders own 22\%, and BK's own $27 \%$. Berkshire Hathaway, who partially funded the merger by providing $\$ 3$ billion, holds a $4.8 \%$ stake (Sorkin, 2014).

The new leadership team is made up of senior executives from the BK and Tim Horton brands. Daniel Schwartz, formerly CEO of BK Worldwide, has been appointed to the role of CEO, Restaurant Brands International. Marc Caira, formerly CEO of Tim Hortons, will serve as vice- chairman of the board of directors of Restaurant Brands International. In addition to Mr. Schwartz and Mr. Caira, the following executives have been appointed to the Restaurant Brands International leadership team:

- Díaz Sesé, President of the Tim Hortons brand

- José Cil, President of the BK brand

- Alex Macedo, President of BK North America

- David Clanachan, President and COO of Tim Hortons Canada 
- Mike Meilleur, President of Tim Hortons US

- Scott Bonikowsky, chief communication and corporate affairs officer

- Heitor Gonçalves, chief people and information officer

- Josh Kobza, CFO

- Cara Piggot, Senior Vice President for supply chain.

- Peter Nowlan, chief marketing officer

- Tammy Sadinsky Martin, Senior Vice President of retail

- Felipe Athayde, Executive Vice President for US development.

- Sami Siddiqui, Executive Vice President of finance (CSP Daily News, 2014).

\subsection{Organisational culture}

Tim Hortons is one of the largest restaurant chains in North America and the largest in Canada. The Canadian icon has early recognised the value of long-term customer relationships and diligently worked since its early establishment to keep it as its ultimate objective. Tim Hortons has united itself into the Canadian identity with such remarkable success that for some it has become intertwined in the very idea of Canadianness. The relationship between the brand and the nation is remarkable and as Tim Horton's loyal customers describe it "there is nothing more Canadian than sipping a double-double or having a box if timbits at a hockey game" (Friesen, 2014). This lifetime customer relationship has stemmed from Tim Horton himself, the former Toronto Maple Leaf defenseman who was an ideal personification of the brand (Friesen, 2014). On the other hand, BURGER KING® is the second largest fast food hamburger restaurant (FFHR) chain in the world. BURGER KING ${ }^{\circledR}$, the original HOME OF THE WHOPPER ${ }^{\circledR}$ was able to differentiate itself from its competitors through its commitment to serve customers with the best quality fast food (CSP Daily News, 2014), which is clearly stated through its mission "We proudly serve the best burgers in the business, plus a variety of real, authentic foods ... all freshly prepared ... just the way you want it" (Barltorik, 2004).

BURGER KING ${ }^{\circledR}$ operates in approximately 14,000 locations serving more than 11 million guests daily in 100 countries and cities worldwide. Most of BURGER KING® restaurants are owned and operated by independent franchisees, many of them family-owned operations that have been in business for decades (CSP Daily News, 2014). Each of the two brands has its own distinctive culture, value, and products that differentiate it from its competitors. In order to face the battle and stay competitive in the global market, BK and Tim Hortons merged together to create the largest fast-food company, Restaurant Brands International Inc.

The deal was approved by the Canadian Competition Bureau on 28 October 2014. However, in order to complete the transaction, the two companies agreed to conditions requiring that the $\mathrm{BK}$ and Tim Hortons chains retain separate operations, not combine locations in Canada and the USA. Each chain will maintain its distinctive brand and differentiate its product from one other; yet will benefit from global scale, reach and sharing of best practices. 


\section{Marketing strategy}

\subsection{Objectives}

Restaurant Brands International owns two of the world's most prominent and iconic QSR brands - TIM HORTONS ${ }^{\circledR}$ and BURGER KING ${ }^{\circledR}$. Restaurant Brands International is the world's third-largest QSR companies with a market value of approximately $\$ 18$ billion and over 18,000 restaurants in 100 countries.

\subsection{Constrains}

As consumers' taste and preferences keep evolving toward healthier eating habits, Restaurant Brand international will be facing challenges in trying to satisfy those health conscious customers and their core customers. Additionally, this new trend in peoples' eating habits have led to the rise of a new segment in the fast food industry. The new emerging fast-casual segment presents new threat to the fast-food industry as people are turning to the new substitute restaurants, which provides healthier menu options at reasonable prices.

\subsection{Target market(s)}

According to a study done by the QSR magazine (Melnick, 2011), it has been found that $54 \%$ of 'super heavy' fast-food users (who eat fast food at least once a day) and $37 \%$ of 'heavy' fast-food users (two to six times per week) are between the ages of 18 and 34 (Oches, 2012). It has also been found that the majority of fast-food consumers are from the lower-middle, and middle-income classes according to a study from the University of California. The study has proven that fast-food visits rose along with annual income up to $\$ 60,000$. As the income increased above 60,000 , the study has shown that visits to fast food restaurants has declined and were replaced with more expensive full-service dining (Melnick, 2011).

\section{Analysis of marketing mix variables}

\subsection{Burger King}

Product: BK is a FFHR chain, which produces: hamburger; cheeseburger, fries, salads, hash browns, onion rings, coffee, juice, shakes, cookies, pies, etc. BK has differentiated itself from competitors by 'have it your way' theme, which allows individualise each orders with many options including fries or onion rings, cheese, bacon, mustard, ketchup, mayonnaise, lettuce, tomato, pickles and onions. Price: BK joined McDonalds in offering value menus like the $\$ 1$ double cheese burger; $\$ 1.29$ Whopper Jr.; 50ф cones; $\$ 1$ frozen lemonades; the 'mix and match' 2 for \$5. Place: BK operates in over 70 countries and $90 \%$ are privately-owned franchise. Under a franchise arrangement, the company owns or leases the land and building, while the franchisees invest in the equipment, seating and décor. Promotion: BK is always looking for ways to offer affordable menus and items for their customers. Also, the company uses heavily the social media networks to offer promotions for the fan community. People: BK pairs its 'have it your way' theme with 
speedy customer service. To expedite service, orders are taken on a continual basis. After an order is taken, the customer then moves down the line where another employee is preparing the order. Meanwhile, the original employee is taking another customer's order. Customers also get their own drinks while they are waiting for their meal (Marketing Teacher, 2015).

\subsection{Tim Hortons}

Tim Hortons is Canada's largest QSR specialising in always fresh coffee, baked goods and home style lunches: product: doughnut holes, coffee, teas, muffins, Danishes. Price: prices range from $\$ 0.25$ to $\$ 1.60$. The company primarily focus on offering value. Place: product is primarily located in shopping malls, highway outlets, universities and hospitals in Canada and some states in the USA. Promotion: the pride themselves on 'winning in the new era' by being bold, being different and being daring.

\section{Summary of marketing strategy's strengths and weaknesses}

Both BK's and Tim Hortons' plans are to continue to function separately; yet benefit from each other by providing opportunities to strengthen their weakness points, increase their purchasing power, advance their marketing and operation efficiencies, and reinforce their opportunity for brand expansion. BK holds a strong position in the fast food market. It operates in over 70 countries and $90 \%$ are privately-owned franchise. BK continues to focus on refranchising all its company-owned restaurants in addition to expanding globally by making franchising more attainable for overseas restaurants. By facilitating franchising processes, BK will be able to control cost and develop an efficient marketing strategy that will appeal to the young, and tight-budget customers (Lutz, 2014). On the other hand, Tim Hortons' strategy is to create long-term profitable growth and above-market returns by delivering the ultimate guest experience, and differentiating its products from its competitors by responding to customers' evolving needs and expectations.

Tim Hortons' future plans are to utilise menu innovations and marketing programs to respond to emerging trends, such as consumer interest in nutrition, health, and wellness. In addition, Tim Hortons' other strategic plan is to 'win in the new era' by focusing on continuous restaurant development and broadening their reach (http://www.timhortons.com). In order to stay competitive in the market and achieve the anticipated financial growth, BK and Tim Hortons have merged together to create a powerful entity that is capable to compete in the global market and overcome some of the shortcomings of each company. For instance, BK has faced fierce competition and low revenues; lack of disruptive innovative products; rise of quality issues across the franchise network; and slow response to customers' developing trend toward healthier lifestyle for adults and children (Big Mac vs. Whooper Burger War, 2014). Likewise, Tim Hortons has had its own flaws, such as declining profitability for franchisees and store owners and slow expansion in the US market (Martinez, 2014). The merger between BK and Tim Hortons has been looked upon as a great opportunity to overcome those weaknesses and achieve broad expansion as well as financial advantages. 


\section{Implication for strategy development}

\subsection{Statement of primary problem(s)}

The fierce competition between fast-food and fast- casual restaurants. As a matter of fact, fast casual companies continue to outpace the quick-service and the full-service markets (Green, 2011). The main issue that BK is facing is the change in consumers eating habits. American customers have started to think more about what they are putting into their body. They are going away from fatty foods and choosing healthier items such as salads and gluten free items. Tim Hortons' biggest issue is their share of the US market.

\subsection{Evidence of problem(s)}

Consumers have shown over the past decade that they are willing to pay more for healthier food and a more elegant environment for their dining experience. McDonalds has tried to change their image by opening McCafe's across the country. This has given McDonalds the best of both worlds because they still have their fast food products, but with a nice café feel. Fast casual restaurants is a relatively new and fast growing segment which lies between fast food restaurants and casual dining restaurants. They provide more customised, freshly prepared and high quality food than traditional QSR, which BK and Tim Hortons are part of.

\subsection{Effects of problem(s)}

Big QSR like BK and Tim Hortons have been facing a huge threat from the fast-casual restaurants as they are losing market share and customers have been leaning toward this type of restaurants and staying away from QSR (Forbes, 2014b). Consumers turning to healthier eating habits is a great change for the American society, but for BK this is going to mean that less people will go to their store to eat, unless they change their menu to include healthy items for this growing market. For Tim Hortons the untapped US market is costing them sales and they are losing their Canadian market little by little every day to Starbucks and other small coffee chains.

\section{Strategic alternatives for solving problems}

- Strategic alternative 1: Centralised management and shared resources will help both companies improve their profitability, brand image, market share, and competitive viability.

- Benefits of alternative 1: Both companies will be sharing resources and have robust financial capital to compete against fast casual restaurants. Moreover, the merger will provide both companies with stronger purchasing power, advanced marketing and operation efficiencies, and broader national and international expansion.

- Costs of alternative 1: Bringing together two of the world most recognised brands in one influential entity is more cost effective than developing new products at each individual company level. 
- Strategic alternative 2: The second alternative would be for both companies to invest in R\&D and revamp their menus and come with healthy choices to attract the rapid growing health-conscious market.

- Benefits of alternative 2: Regain market share from the fast-casual segment.

- Costs of alternative 2: Modifying their menus by removing high fat, high calorie items and replacing them with healthy, low fat, low calorie items may be costly initially, however, it will pay off as more health-conscious customers will be attracted to the industry.

\section{Selection of strategic alternative and implementation}

Combining the two companies in to one dominant entity will be more powerful, resourceful, and influential. Both companies will benefit from the shared resources and centralised management and will result in increased revenue, improved purchasing power, competitive advantage, and market efficiency.

\section{Summary, conclusions and recommendations}

Tim Hortons and BK's union created the third-largest fast food business in the world; however, both companies maintain separate operations after the merger. Tim Hortons is Canada's leading QSR chain while BK is the second largest fast food hamburger chain globally. Tim Hortons has a fully-franchised business model including a vertically integrated system. They own five distribution centres, two coffee-roasting businesses, and a fondant facility. They are able to leverage their scale in Canada through key supply chain activities that provide an increase in efficiencies, competitive advantage, and quality/timely deliveries to their restaurants. Through their supply chain model, Tim Hortons is able to maximise their profitability and provide better returns to their shareholders.

Lastly, they are able to leverage their brand awareness in Canada to expand further in the US and internationally. Tim Hortons has a record of consistent long-term growth in store counts and sales. In order for Tim Hortons to continue their success, the company must focus on their customers' needs. Competition is fierce in the US and consumer trends are evolving. They will need to protect their current market share in Canada while expanding in the US and overseas. Keys areas of focus will need to include customer experience, innovation, and disciplined management and execution.

\section{References}

Baer (2012) Flashback Friday - 'Have It Your Way' [online] https://baerpm.com/2012/02/ 17/flashback-friday-have-it-your-way/ (accessed 17 February 2012).

Barltorik, P. (2004) 'Burger King Corporation says 'PAY IT YOUR WAY', Business Wire, 21 July [online] https://www.businesswire.com/news/home/20040721005219/en/Burger-KingCorporation-PAY-VeriFone-Omni-3750.

Big Mac vs. Whooper Burger War (2014) [online] https://bigmacvswhooper.wordpress.com/ category/strategy/strengths-weaknesses/ (accessed 1 November 2014). 
Caira, M. (2013) Tim Hortons Inc. Announces Appointment of Marc Caira as New President and CEO: Seasoned Nestlé SA Global Foodservices Executive to Join Tim Hortons in July 2013, Oakville, Ontario [online] https://www.timhortons.com/ca/en/corporate/newsrelease.php?id=8155 (accessed 8 May 2013).

CSP Daily News (2014) 'Tim Hortons, Burger King Now Restaurant Brands International new quick-service restaurant chain combo nabs 'QSR' stock symbol' [online] https://www.cspdailynews.com/foodservice/tim-hortons-burger-king-now-restaurant-brandsinternational (accessed 16 December 2014).

Daszkowski, D. (2018) Short History of Burger King [online] https://www.thebalancesmb.com/ history-of-burger-king-1350968 (accessed 9 December 2018).

Evans, P. (2014) Tim Hortons, Burger King Agree to Merger Deal [online] http://www.cbc.ca/ news/business/tim-hortons-burger-king-agree-to-merger-deal-1.2746948 (accessed 26 August 2014).

Forbes (2014a) Burger King-Tim Hortons Cross-Border Merger Much More Than Tax Inversion [online] http://www.forbes.com/sites/greatspeculations/2014/08/29/burger-king-tim-hortonscross-border-merger-much-more-than-tax-inversion/ (accessed 29 August 2004).

Forbes (2014b) How the Fast Casual Segment is Gaining Market Share in the Restaurant Industry? [online] http://www.forbes.com/sites/greatspeculations/2014/06/23/how-the-fast-casualsegment-is-gaining-market-share-in-the-restaurant-industry/ (accessed 29 August 2004).

Friesen, J. (2014) 'Tim Hortons: How a brand became part of our national identity', The Globe and Mail, 27 August, Vancouver, Canada, https://www.theglobeandmail.com/news/national/timhortons-how-a-brand-became-part-of-our-national-identity/article20217349/.

Hodge, S.A. (2012) Countdown is Over. We're \#1 [online] https://taxfoundation.org/countdownover-were-1/ (accessed 1 April 2012).

Hunter, D. (2012) Double Double: How Tim Hortons Became a Canadian Way of Life, One Cup at a Time, 9 October, HarperCollins Publishers.

Hunter, D. (2018) Tim Hortons, The Canadian Encyclopedia [online] https://www. thecanadianencyclopedia.ca/en/article/tim-hortons (accessed 31 January 2018).

Inskeep, S. (2014) Burger King Announces Merger with Tim Hortons, Move To Canada [online] https://www.npr.org/2014/08/26/343420295/burger-announces-merger-with-tim-hortonsmove-to-canada (accessed 26 August 2014).

International Business Times (2014) Burger King Could Dodge \$1.2 Billion in US Taxes through 2018 with Tim Horton's Merger: Americans for Tax Fairness [online] http://www.ibtimes.com/burger-king-could-dodge-12-billion-us-taxes-through-2018-timhortons-merger-americans-1748021 (accessed 11 December 2018).

Lutz, A. (2014) How Burger King Completely Turned Business Around, Business Insider [online] http://www.businessinsider.com/burger-kings-new-strategy-2014-12 (accessed 12 December 2014).

Marketing Teacher (2015) Burger King Marketing Mix [online] http://www.marketingteacher.com/ burger-king-marketing-mix/ (accessed 9 May 2014).

Martinez, P. (2014) Tim Hortons: Strengths, Weaknesses, Opportunities, Threats [online] http://www.fool.ca/2014/06/19/tim-hortons-strengths-weaknesses-opportunities-threats/ (accessed 19 June 2014).

Maze, J. (2014) Tim Hortons Shareholders Approve Acquisition by Burger King, Nation's Restaurant News [online] http://nrn.com/mergers-acquisitions/tim-hortons-shareholdersapprove-acquisition-burger-king (accessed 9 December 2014).

McBride, W. (2014) How Much Lower are Canada's Business Taxes? [online] https://taxfoundation.org/how-much-lower-are-canadas-business-taxes/ (accessed 26 August 2014).

McKinnon, J. (2014) Obama Urges Quick Action to Stop 'Inversions' [online] http://www.WSJ.com (accessed 24 July 2014). 
Melnick, M. (2011) Fast Food's Biggest Customer: Not the Poor, But the Middle Class [online] http://healthland.time.com/2011/11/07/fast-foods-biggest-customers-not-the-poor-but-themiddle-class/ (accessed 7 November 2011).

Oches, S. (2012) Consumer Trend. Meet Your Consumer, QSR [online] http://www.qsrmagazine.com/consumer-trends/meet-your-consumer (accessed November 2012).

Penfold, S. (2008) The Donut: A Canadian History, 1st ed., Scholarly Publishing Division, University of Toronto Press.

Raice, S. (2014) 'How Tax Inversions Became the Hottest Trend in M\&A, Wall Street Journal (WSJ) [online] https://www.wsj.com/articles/how-tax-inversions-became-the-hottest-trend-inm-a-1407240175 (accessed 5 August 2014).

Reuters, T. (2010) Burger King Holdings Inc. [online] https://www.rbi.com/Cache/1500094506. $\mathrm{PDF} ? \mathrm{O}=\mathrm{PDF} \& \mathrm{~T}=\& \mathrm{Y}=\& \mathrm{D}=\& \mathrm{FID}=1500094506 \& \mathrm{iid}=4591210$ (accessed 31 December 2010).

Sorkin, A. (2014) Buffett Greases $\$ 11 B$ Burger King-Tim Hortons Deal [online] https://www.cnbc.com/2014/08/26/buffett-to-help-finance-burger-kings-acquisition-of-timhortons.html (accessed 26 August 2014).

Statica (2019) Statistics on 'Restaurant Brands International' [online] http://www.statica.com (accessed 26 February 2019).

Taylor, K. (2014) Burger King Posts Strong U.S. Sales Growth as McDonald's Flounders [online] http://www.Entrepreneur.com (accessed 4 November 2014).

Viera, P. (2014) Canada Approves Burger King's Deal to Buy Tim Hortons [online] https://www.wsj.com/articles/canada-approves-burger-kings-deal-to-buy-tim-hortons1417728183 (accessed 4 December 2014).

Woodland, M. (2014) Canada Has the Most Business-Friendly Tax Policy in the World, Business Insider [online] https://www.businessinsider.com/canada-corporate-tax-rate-2014-8 (accessed 25 August 2014).

York, E.B. (2010) Burger King to be Acquired in a \$3.3-Billion Buyout [online] https://www.latimes.com/archives/la-xpm-2010-sep-03-la-fi-burger-king-20100903-story.html (accessed 3 September 2010).

\section{Websites}

http://www.zacks.com/stock/news/157418/longawaited-burger-kingtim-hortons-merger-completed http://www.trefis.com/stock/bkw/model/trefis?freeAccessToken=PROVIDER 3b70bde78c7b901c cb746875c3e13f1 167bb8d5d

http://www.meattradenewsdaily.co.uk/news/260510/usa__burger_king_and_franchise_problems.a spx

https://www.statista.com/statistics/377371/planned-frequency-of-dining-out-in-the-next-12months-us/

http://business.financialpost.com/2013/07/18/why-tim-hortons-is-failing-to-score-in-america/

http://www.theguardian.com/world/us-money-blog/2015/feb/01/tim-horton-burger-king-mergerlayoffs-canada

http://business.financialpost.com/2014/08/30/burger-king-will-turn-tim-hortons-into-iconic-globalbrand-miles-nadal-says/

http://www.forbes.com/sites/greatspeculations/2014/07/01/key-trends-impacting-burger-kingsbusiness

http://www.mbaskool.com/brandguide/food-and-beverages/10316-tim-hortons.html

http://www.cbc.ca/news/business/tim-hortons-burger-king-reaction-u-s-cracks-down-on-taxinversions- 1.2774913 
http://www.forbes.com/sites/greatspeculations/2014/08/29/burger-king-tim-hortons-cross-bordermerger-much-more-than-tax-inversion/2/

http:/healthland.time.com/2011/11/07/fast-foods-biggest-customers-not-the-poor-but-the-middleclass 